\title{
Development of barnyard millet ready-to-eat snack food : Part II
}

\author{
R.V. Jaybhaye and P.P. SRIVAstaV
}

Barnyard millet (BM) based hot air puffed product has less crispness. Oven toasting improves the crispness of the puffed, roasted or flaked food products. A ready-to-eat (RTE) puffed and toasted snack food product from BM was developed. Toasting experiments were designed using central composite rotatable design (CCRD) at varying temperature $\left(84-126^{\circ} \mathrm{C}\right)$ and time $(10-30 \mathrm{~min})$. There was significant reduction in moisture content, colour and hardness of toasted product with increase in toasting temperature and time whereas there was higher increase in crispness at lower levels but less increase at higher levels of toasting parameters. The influence of temperature was dominant over toasting time for all responses. Reduction in moisture content and improvement in microstructure of the product during toasting resulted in the significant increase in crispness. The process parameters were optimized using response surface methodology (RSM). The quality attributes like moisture content, colour, crispness and hardness of the optimally toasted snack food were $0.046 \mathrm{~kg} \mathrm{~kg}^{-1} \mathrm{dm}, 69.79,18.45$ and $362.64 \mathrm{~g}$, respectively at the optimum temperature and time combination of 116.26 ${ }^{\circ} \mathrm{C}$ and $20.23 \mathrm{~min}$, respectively. The total energy content of the BM snack food was $380.74 \mathrm{kcal}$ per $100 \mathrm{~g}$ product.

Key Words : Toasting, Crispness, Haedness, Responses, Quality attributes

How to cite this article : Jaybhaye, R.V. and Srivastav, P.P. (2015). Development of barnyard millet ready-to-eat snack food : Part II. Food Sci. Res. J., 6(2): 285-291. 